\title{
THE IMPLICATIONS OF USING STEREOTYPES
}

\author{
Gabriela-Maria MAN \\ "Lucian Blaga" University, Sibiu, Romania \\ gabriela.man@ulbsibiu.ro
}

\begin{abstract}
The term stereotype was first used around a century ago, but its meaning and implications are relevant today due to an increase in group diversity and interactions. Stereotypes are simplistic and generalized beliefs about group members that can have negative consequences. This article reviews some of the evidence relating to two of the most common implications of stereotypes; discrimination and changes in cognitive and physical performance related with stereotype threat. The findings from this article may be helpful for human resource (HR) specialists, professors, health related specialists and those engaged in evaluation activities.
\end{abstract}

KEYWORDS: stereotypes, diversity, discrimination, stereotype threat

\section{Introduction}

Almost a century after the introduction of the term 'stereotype' (Davidio, Hewstone, Glick, \& Esses, 2010) it is necessary to study the concept and understand its implications. This is particularly true today due to the increase in workforce diversity (Saxena, 2014), high migration rates in many countries (Organization for Economic Cooperation and Development [OECD], 2019) and greater technological connectivity. Technological advancements including the internet and social media have created opportunities for people to work and interact with each other across the world. Today, social diversity is visible in the interaction of people with different demographics, and with various attitudes, values and backgrounds who belong to different groups.

Diversity and the interaction of people from different groups is often associated with the occurrence of both individual and collective stereotypes (Mackie, Hamilton, Susskind, \& Rosselli, 1996).
A stereotype refers to a generalized belief or cognitive schema used to characterize a specific group; those beliefs and expectations are extended to its members (Davidio et al., 2010). Stereotypes are not always erroneous, and in some circumstances can facilitate operation with a large volume of information (Blaine \& McClure Brenchley, 2016). However, due to the fact that stereotypes are generalized beliefs, they can lead to negative effects and also to discrimination.

The aim of this article is to briefly review the evidence related with the negative aspects associated and generated by the stereotypes. In this regard, the literature will be reviewed taking into account two of the most common effects of stereotypes, namely discrimination and stereotype threat.

\section{Method}

Literature search. In order to evidence the negative impact of stereotyping, a literature search was performed. Stereotype, stereotype threat, discrimination, and in conjunction with the phrase stereotype

DOI: 10.2478/raft-2020-0040

(C) 2017. This work is licensed under the Creative Commons Attribution-NonCommercial-NoDerivs 3.0 License. 
threat/discrimination: health, performance, organization, were the keywords used for searching multiple databases.

Inclusion criteria. Although articles were targeted for this brief review, books were not excluded. However, unpublished studies and dissertations were excluded. The literature included only publications from the last 25 years. This review takes into account different kinds of studies, from experiments to correlational studies.

\section{The Impact of Stereotypes on Performance}

In recent studies of stereotypes, a new concept has emerged; namely the stereotype threat. This is defined as " $a$ situation in which there is a negative stereotype about a persons' group, and he or she is concerned about being judged or treated negatively" (Spencer, Logel, \& Davies, 2016, p. 416). Studies related to the stereotype threat reveal that when a person is exposed to situations where she/he may confirm the negative stereotype associated with her/his group, changes in performance may occur.

The first studies evaluating these changes in performance were based on verbal tests of African-American participants who were exposed to negative stereotypes related to their group (Steele \& Aronson, 1995). Since then many other studies have revealed performance impairments in many domains and for many different social groups who have been negatively stereotyped.

\subsection{Cognitive Performance and the Stereotype Threat}

Since 1995 there has been a lot of evidence revealing changes in performance for different cognitive tasks on the part of participants who have been previously informed (in different ways) that the group they belong to, in general, has a lower level of performance.

Older adults are often negatively stereotyped (Bodner, 2009). Therefore, when they are exposed to negative stereotypes about their memory (the negative stereotype that portrays them as having memory problems) they underperform in memory tests when compared to other older adults who have not been exposed to this negative stereotype (Armstrong, Gallant, Li, Patel, \& Wong, 2017).

Women belong to a social group that is often stereotyped as less competent (Glick \& Fiske, 2001). When women are exposed to this negative stereotype their performance is impaired when compared to those women not exposed to this negative stereotype or compared to men. Empirical evidence reveals that in these particular situations the ability to learn is impaired (Sekaquaptewa \& Thompson, 2003). It is also found that mathematics results are worse in experimental situations where women are exposed to negative stereotypes (Picho, Rodriguez, \& Finnie, 2013). This is also true in physics performance tests (Marchand \& Taasoobshirazi, 2013), in engineering examinations (Bell, Spencer, Iserman, \& Logel, 2003). All the above-mentioned areas - physics, mathematics, engineering and so on - are perceived by society as areas in which men would perform better then women. Therefore, when such stereotypes are presented to women, when they perform tasks in these areas of activity, their performance diminishes.

There is a large body of research that demonstrates that men's performance also decreases when they are exposed to negative stereotypes related to their own group. For instance, men are usually stereotyped as less competent than women in verbal tasks. When men have to perform a verbal task and are negatively gender stereotyped (as a social group with lower performance in verbal areas) they underperform in verbal tasks (Hirnstein, Coloma Andrews, \& Hausmann, 2014) compared to men not exposed to this negative stereotype. Male participants also underperform in tasks that require the 
decoding of non-verbal cues when they are previously told that women perform better on this type of task (Koenig \& Eagly, 2005). There are many other examples to be found.

\subsection{Physical Performance and the Stereotype Threat}

The impact of the stereotype threat is not only identified in the cognitive area, it can also influence physical performance. For instance, when a particular social group is stereotyped as being physically incompetent or more fragile, and members of that group have to perform a physical task, under the pressure of this negative stereotype when the negative stereotype is highlighted, their performance in that particular task may decrease. This may be the case with regard to older adults who are stereotyped negatively when it comes to their physical abilities. One study, for instance, revealed that in the case of older adults exposed to this stereotype, their hand grip was impaired by up to $50 \%$ (Swift, Lamont, \& Abrams, 2012).

Negative stereotypes also exist about the physical performance of women and studies reveal that women's physical performance is affected when they are exposed to negative gender stereotypes compared to situations when they are not. This can be seen in the case of performance in athletics (Hively \& El-Alayli, 2014), soccer (Chalabaev, Sarrazin, Stone, \& Cury, 2008), and so on.

However, there are some studies that did not identify any changes in physical performance when there was a stereotype threat. For example, this was reported by the study of Horton, Baker, Pearce, and Deakin (2010).

\subsection{The Implications of the Stereotype Threat}

The stereotype threat has been shown to produce performance impairment in men and women and in different age groups but there are also many other social groups affected by negative stereotypes. For example, Caucasian adults underperform in mathematics tasks when they are told that are competing alongside Asian adults (Asian adults are often stereotyped as superior in mathematics compared to Caucasian adults) (Aronson, Lustina, Good, Keough, Steele, \& Brown, 1999).

The impairments in performance for negatively stereotyped groups are visible especially when completing difficult tasks and in tasks with high constraints (Allison, Redhead, \& Chan, 2017). There are also some situations where exposure to negative stereotypes may increases performance in the negatively stereotyped group (Deshayes, Zory, Seitchik, Chalabaev, \& ClementGuillotin, 2019). Still, the negative impact of the stereotype threat on performance causes concern in organizations due to the fact that, as previously mentioned, workplace diversity has increased.

Empirical evidence from organizational psychology points to the fact that the stereotype threat can reduce job engagement, career aspirations (Casad, \& Bryant, 2016). It is also associated with reduced work-related well-being (Von Hippel, Sekaquaptewa, \& McFarlane, 2015), with negative job attitudes and an increase in intentions to resign from work (Von Hippel, Kalokerinos, \& Henry, 2013). The specialists (e.g. managers, academics, teachers) involved in performance evaluations need to be aware of the stereotype threat and understand how sometimes the fear of confirming a negative social stereotype can account for impairments in performance in many tasks, for negative stereotyped group members.

\section{Stereotypes and Discrimination}

The concept of discrimination is relevant to the study of stereotypes because stereotypes act as conditions for discriminatory behavior and for the perception of the discrimination as well (Voss, Bodner, \& Rothermund, 2018). 
Holding a certain stereotype about a particular group does not necessarily translate into discriminatory behavior towards those group members.

Discrimination is often defined as "treating differently, negatively and adversely people" on the basis of their group membership (Marsh \& SahinDikmen, 2003, p. 5).

As discrimination is often reported by many members of different social groups (Boutwell et al., 2017) it raises concerns among various specialists, these include health professionals. Empirical evidence shows that discrimination has many implications at individual level. For instance, a meta-analysis revealed that discrimination influences mental and physical health (Pascoe \& Smart Richman, 2009), and it is also associated with perceived high levels of stress (Flores, Tschann, Dimas, Bachen, Pasch, \& de Groat, 2008).

Discrimination can be found in the organizational context as well and it seems to be associated with many costs, for both the employees and for the organization. For example, discrimination at work is associated with decreased job satisfaction and organizational citizenship behavior (Ensher, Grant-Vallone, \& Donaldson, 2001) and increased work absenteeism (Min, Park, Kim, \& Min, 2013) (there are many examples).

\section{Conclusions}

When workplace and social diversity is generally high, as it is today, an analysis of the implications of stereotypes is necessary because they may emerge when diverse groups of people interact.

Stereotypes refer to the evaluations made about particular individuals based on their group membership. Although stereotypes are not always entirely erroneous they often, due to simplistic evaluations, lead to negative outcomes such as discrimination and the stereotype threat.

The stereotype threat is related to the fear people might feel to confirm a negative stereotype about their group. This fear can lead to changes in their cognitive and physical performance. This means that, in certain situations, members of a particular group that are negatively stereotyped would perform better if they were not exposed to these negative stereotypes. This information is relevant to professionals who evaluate the performance of different individuals. These professionals must ensure that the people being assessed are not exposed to stereotypes when they are evaluated.

Discrimination, on the other hand, is when members of a particular group of people are treated differently and negatively because they belong to a specific group. Discrimination is another element associated with multiple implications at the individual, organizational and social level.

\section{REFERENCES}

Allison, C., Redhead, E. S., \& Chan, W. (2017). Interaction of task difficulty and gender stereotype threat with a spatial orientation task in a virtual nested environment. Learning and Motivation, 57, 22-35. doi:10.1016/j.lmot.2017.01.005.

Armstrong, B., Gallant, S. N., Li, L., Patel, K., \& Wong, B. I. (2017). Stereotype threat effects on older adults' episodic and working memory: A meta-analysis. The Gerontologist, 57(suppl_2), S193-S205. doi:10.1093/geront/gnx056.

Aronson, J., Lustina, M. J., Good, C., Keough, K., Steele, C. M., \& Brown, J. (1999). When white men can't do math: Necessary and sufficient factors in stereotype threat. Journal of Experimental Social Psychology, 35(1), 29-46. doi:10.1006/jesp.1998.1371. 
Bell, A. E., Spencer, S. J., Iserman, E., \& Logel, C. E. R. (2003). Stereotype threat and women's performance in engineering. Journal of Engineering Education, 92(4), 307-312. doi:10.1002/j.2168-9830.2003.tb00774.x.

Blaine, B. E., \& McClure Brenchley, K. J. (2016). Understanding the psychology of diversity. Thousand Oaks, CA: Sage Publications

Bodner, E. (2009). On the origins of ageism among older and younger adults. International Psychogeriatrics, 21(06), 1003-1014. doi:10.1017/s104161020999055x.

Boutwell, B. B., Nedelec, J. L., Winegard, B., Shackelford, T., Beaver, K. M., Vaughn, ... Wright, J. P. (2017). The prevalence of discrimination across racial groups in contemporary America: Results from a nationally representative sample of adults. PloS One, 12(8), e0183356. https://doi.org/10.1371/journal.pone.0183356.

Casad, B. J., \& Bryant, W. J. (2016). Addressing stereotype threat is critical to diversity and inclusion in organizational psychology. Frontiers in Psychology, 7, 1-18. doi:10.3389/fpsyg.2016.00008.

Chalabaev, A., Sarrazin, P., Stone, J., \& Cury, F. (2008). Do achievement goals mediate stereotype threat? An investigation on females' soccer performance. Journal of Sport and Exercise Psychology, Human Kinetics, 30, 143-158.

Davidio, J. F., Hewstone, M., Glick, P., \& Esses, V. M. (2010). Prejudice, stereotyping and discrimination: Theoretical and empirical overview. In J. F. Dovidio, M. Hewstone, \& P. Glick, \& V. M. Esse (Eds.) The SAGE handbook of prejudice, stereotyping and discrimination (pp. 3-28). Thousand Oaks, CA: Sage Publications

Deshayes, M., Zory, R., Seitchik, A. E., Chalabaev, A., \& Clement-Guillotin, C. (2019). Can stereotype threat increase women's performance? The case of a fatiguing task. Sport, Exercise, and Performance Psychology. Advance online publication. https://doi.org/10.1037/ spy0000190.

Ensher, E., Grant-Vallone, E., \& Donaldson, S. (2001). Effects of perceived discrimination on job satisfaction, organizational commitment, organizational citizenship behavior, and grievances. Human Resource Development Quarterly, 12, 53-72. 10.1002/1532-1096(200101/02)12:13.0.CO;2-G.

Flores, E., Tschann, J. M., Dimas, J. M., Bachen, E. A., Pasch, L. A., \& de Groat, C. L. (2008). Perceived discrimination, perceived stress, and mental and physical health among mexican-origin adults. Hispanic Journal of Behavioral Sciences, 30(4), 401-424.

Glick, P., \& Fiske, S. T. (2001). An ambivalent alliance: Hostile and benevolent sexism as complementary justifications for gender inequality. American Psychologist, 56(2), 109-118. https://doi.org/10.1037/0003-066X.56.2.109

Hirnstein, M., Coloma Andrews, L., \& Hausmann, M. (2014). Gender-stereotyping and cognitive sex differences in mixed- and same-sex groups. Archives of Sexual Behavior, 43(8), 1663-1673. doi:10.1007/s10508-014-0311-5.

Hively, K., \& El-Alayli, A. (2014). You throw like a girl: The effect of stereotype threat on women's athletic performance and gender stereotypes. Psychology of Sport and Exercise, 15(1), 48-55. doi:10.1016/j.psychsport.2013.09.001.

Horton, S., Baker, J., Pearce, W., \& Deakin, J. M. (2010). Immunity to popular stereotypes of aging? Seniors and stereotype threat. Educational Gerontology, 36(5), 353-371. http://dx.doi.org/10.1080/03601270903323976.

Koenig, A. M., \& Eagly, A. H. (2005). Stereotype threat in men on a test of social sensitivity. Sex Roles, 52(7-8), 489-496. doi:10.1007/s11199-005-3714-x. 
Marchand, G. C., \& Taasoobshirazi, G. (2013). Stereotype threat and women's performance in physics. International Journal of Science Education, 35(18), 3050-3061. doi:10.1080/09500693.2012.683461.

Marsh, A., \& Sahin-Dikmen, M. (2003). Discrimination in Europe. (Raport 57.0). European Commission website, available at: https://ec.europa.eu, accessed on 18 September 2020 .

Min, J.-Y., Park, S.-G., Kim, S.-S., \& Min, K.-B. (2013). Workplace injustice and selfreported disease and absenteeism in South Korea. American Journal of Industrial Medicine, 57(1), 87-96. doi:10.1002/ajim.22233.

Organisation for Economic Cooperation and Development. (2019). International migration outlook 2019, available at: https://doi.org/10.1787/c3e35eec-en, accessed on 18 September 2020.

Pascoe, E. A., \& Smart Richman, L. (2009). Perceived discrimination and health: A meta-analytic review. Psychological Bulletin, 135(4), 531-554.

Picho, K., Rodriguez, A., \& Finnie, L. (2013). Exploring the moderating role of context on the mathematics performance of females under stereotype threat: A meta-analysis. The Journal of Social Psychology, 153(3), 299-333. doi:10.1080/00224545.2012.737380.

Saxena, A. (2014). Workforce diversity: A key to improve productivity. Procedia Economics and Finance, 11(1), 76-85. doi:10.1016/s2212-5671(14)00178-6.

Sekaquaptewa, D., \& Thompson, M. (2003). Solo status, stereotype threat, and performance expectancies: Their effects on women's performance. Journal of Experimental Social Psychology, 39, 68-74.

Spencer, S. J., Logel, C., \& Davies, P. G. (2016). Stereotype Threat. Annual Review of Psychology, 67(1), 415-437. doi:10.1146/annurev-psych-073115-103235.

Steele, C. M., \& Aronson, J. (1995). Stereotype threat and the intellectual test performance of African Americans. Journal of Personality and Social Psychology, 69(5), 797-811. doi:10.1037/0022-3514.69.5.797.

Swift, H. J., Lamont, R. A., Abrams, D. (2012). Are they half as strong as they used to be? An experiment testing whether age-related social comparisons impair older people's hand grip strength and persistence. BMJ Open, 2(3), 1-6.

Von Hippel, C., Kalokerinos, E. K., \& Henry, J. D. (2013). Stereotype threat among older employees: Relationship with job attitudes and turnover intentions. Psychology and Aging, 28(1), 17-27. doi:10.1037/a0029825.

Von Hippel, C., Sekaquaptewa, D., \& McFarlane, M. (2015). Stereotype threat among women in finance. Psychology of Women Quarterly, 39(3), 405-414. doi: $10.1177 / 0361684315574501$.

Voss, P., Bodner, E., \& Rothermund, K. (2018). Ageism: the relationship between age stereotypes and age discrimination. In L. Ayalon \& C. Tesch-Römer (Eds.) Contemporary perspectives on ageism (pp. 11-32). Cham: Springer. 